\title{
Aplicación del Aprendizaje Basado en Proyectos como estratégia pedagógica para el curso virtual de Antropología Visual en la Universidad Nacional Abierta y a Distancia - UNAD
}

\author{
Uliana Molano ${ }^{1}$
}

La Universidad Nacional Abierta y a Distancia UNAD, posee la mayor cantidad de estudiantes en el país y además demuestra una amplia diversidad en la caracterización de su población, en gran medida por ser a distancia y su carácter de virtual, lo que posibilita el acceso educativo a personas de distintas regiones o condiciones sociales. Este es un punto clave que se debe tener en cuenta y potenciar a la hora de diseñar un curso de antropología.

El curso de Antropología Visual hace parte del ciclo de fundamentación del programa de Artes Visuales, es de carácter obligatorio, disciplinar y teórico, el cual deben cursar los estudiantes antes de tomar la elección de la línea de profundización, aproximadamente en el tercer periodo académico.

El objetivo central del curso es "brindar elementos conceptuales para que el estudiante reconozca y comprenda el campo de la antropología visual mediante el análisis de diversas herramientas metodológicas y prácticas sobre las narrativas audiovisuales que se emplean en los estudios socioculturales y donde el arte puede intervenir para contribuir en la reflexión sobre la realidad y la transformación social". En tal sentido, "el propósito del curso es propiciar en el estudiante una posición crítica y propositiva para desarrollar propuestas de investigación, acción e intervención desde el campo del arte, en la construcción de lecturas sobre la identidad y el patrimonio cultural en medio de la sociedad globalizada".

(Molano, U., 2016). Así mismo, posibilitar en los alumnos el desarrollo de habilidades de comunicación y uso de las narrativas audiovisuales por medio de la aplicación de herramientas de registro antropológico tales como la entrevista, fotografía, el documental y la videografía.

Conceptualmente, el curso tiene tres ejes temáticos: el primero unidad aborda "El campo de la antropología visual" visto desde el análisis etnográfico, los precursores de la observación etnográfica y las herramientas utilizadas en los estudios culturales.

\footnotetext{
${ }^{1}$ Lic. En Lingüística y Literatura de la U. Distrital Francisco José de Caldas, Antropóloga y Maestra en Museología y Gestión de Patrimonio de la U. Nacional de Colombia. Docente del Programa de Artes Visuales, Escuela de Ciencias Sociales Artes y Humanidades de la Universidad Nacional Abierta y a Distancia UNAD. Correo: uliana.molano@unad.edu.co ORCID: http://orcid.org/0000-0002- 5087-0026
} 
El segundo trata sobre el "Desarrollo de la antropología visual" desde una perspectiva histórica en la que se observan las diversas posturas conceptuales, metodológicas y narrativas de la fotografía y el documental etnográfico. El tercero pretende un acercamiento a las "Perspectivas actuales de la antropología visual", desde la comunicación y el análisis semiótico de la imagen, fundamentales para aportar valor a las nuevas narrativas, los lenguajes transmedia y el arte como interlocutor a las dinámicas socioculturales, especialmente en el ámbito latinoamericano.

Como en la gran mayoría de cursos de antropología visual, el estudiante abordará el análisis de múltiples productos audiovisuales que van desde los clásicos de la fotografía de viajeros y expedicionarios, al cine y el documental etnográfico, hasta ejercicios más recientes con lenguajes multimediales en entornos virtuales.

Adicionalmente, como estrategia pedagógica se optó por implementar el Aprendizaje Basado en Proyectos ( $\mathrm{ABPr}$ ), en el cual se potencia ese carácter diverso que tienen nuestros estudiantes en un "aprender haciendo", al promover la creatividad orientada a la aplicación de las herramientas de registro audiovisual y el uso de narrativas interdisciplinarias a partir de la observación de los territorios de cada estudiante. Durante el proceso los alumnos diseñan, implementan y evalúan un proceso de investigación etnográfica sobre un tema que se aplica en sus contextos locales.

Durante el primer año de implementación del curso se escogió como título guía del proyecto "Somos lo que comemos" el cual es un pretexto para llegar a las prácticas culturales gastronómicas y sus múltiples problemáticas. En este caso, se usa la comida como un pretexto para llegar a lo que somos como cultura.

El desarrollo de la estratégia pedagógica se hace por fases, encadenada una a otra, con una serie de pasos que nos van llevando a la producción de a un trabajo final pero donde lo importante es el camino de aprendizaje y reflexión.

En la primera fase los estudiantes formulan su proyecto de investigación, eligen un tema puntual, relacionado con la gastronomía cultural de sus regiones, puede ser un plato, un producto, un lugar. Luego problematizan el tema, lo contextualizan, buscan las personas que van a abordar.

En la segunda fase plantean una crónica fotográfica, en la que ya comienzan su proceso de observación y de escritura con un enfoque etnográfico. En este punto se construye una narrativa muy particular a cada caso, una forma de contar, de sensibilizar, muy subjetiva. 
La tercera fase se aborda la entrevista y la historia de vida. Se recolecta material audiovisual con los relatos de las personas que saben de una tradición culinaria y más allá de eso, cómo la comida juega un papel importante en su familia, su territorio, como nos une.

La cuarta fase ya es de elaboración de una videografía o corto documental donde se integra todo el proceso de investigación del estudiante. Se hace uso de las entrevistas elaboradas en la tercera fase o visual recolectado en la segunda fase.

La última fase tiene unos fines pedagógicos de corrección y retroalimentación del trabajo. Sin embargo, se convirtió en el espacio para desarrollar un macroproyecto colectivo que integrase todos productos, no solo de un periodo académico sino que trascienda a un producto de mayor envergadura, en una plataforma multimedia. El resultado pone de manifiesto una diversidad de saberes y sabores muy escondidos y que hacen parte de nuestra identidad.

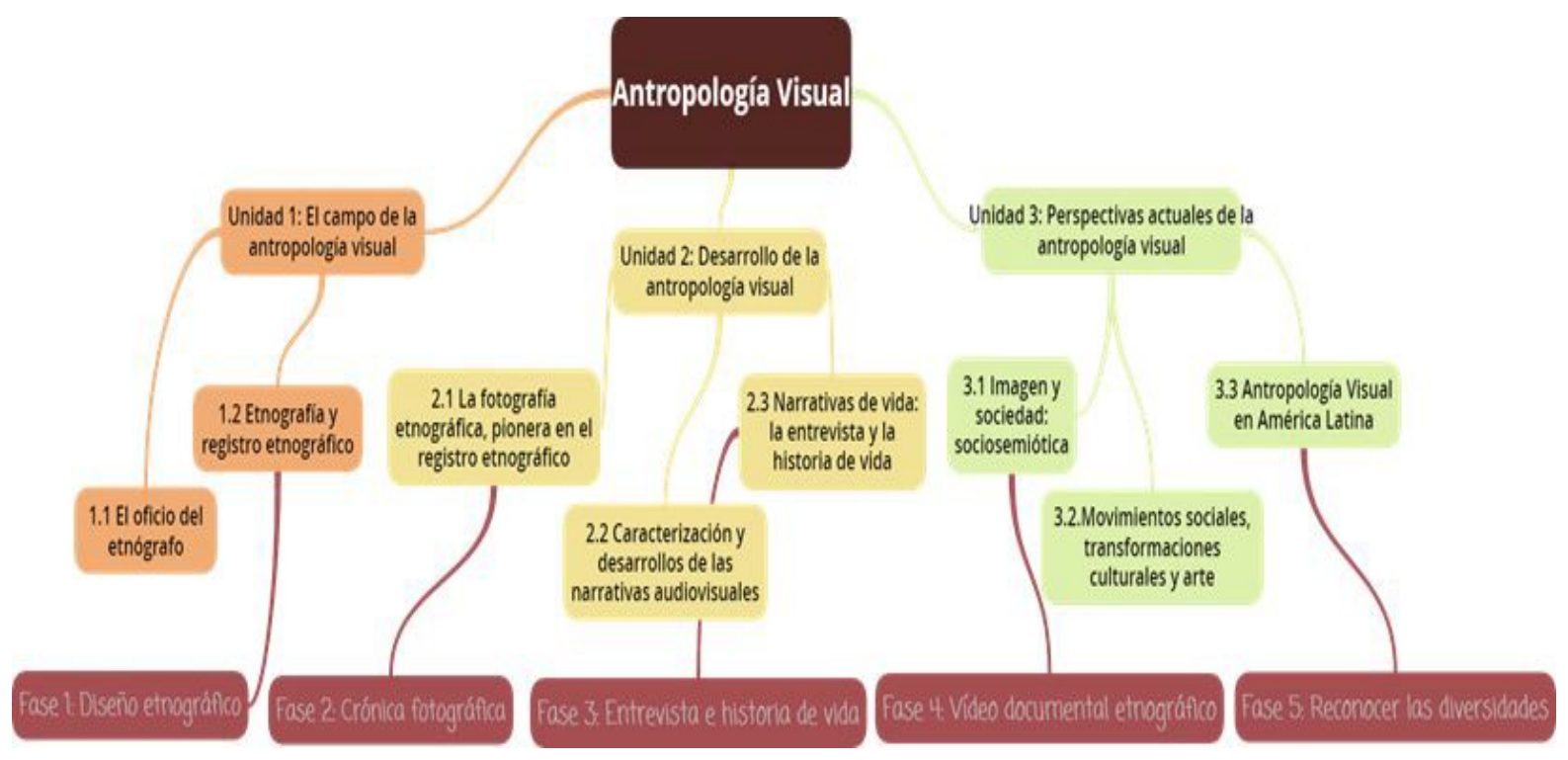

\section{Referencias Bibliográficas}

Molano, U. (2016). Syllabus del Curso de Antropología Visual. Programa de Artes Visuales. Universidad Nacional Abierta y a Distancia UNAD, Bogotá, D.C. 